\title{
Is amyloid plaque imaging the key to monitoring brain pathology of Alzheimer's disease in vivo?
}

\author{
John Hardy ${ }^{1}$, Agneta Nordberg ${ }^{2}$ \\ ${ }^{1}$ Laboratory of Neurogenetics, National Institute on Aging, National Institutes of Health, Building 35, 35 Convent Drive, \\ Room 1A1015 MSC 3707, Bethesda, MD 20892-3707, USA \\ 2 Neurotec Department, Karolinska Institutet, Karolinska University Hospital Huddinge B84, 141 86, Stockholm, Sweden \\ Published online: 4 March 2005 \\ (c) Springer-Verlag 2005
}

Eur J Nucl Med Mol Imaging (2005) 32:519

DOI $10.1007 / \mathrm{s} 00259-004-1758-8$

\section{Eur J Nucl Med Mol Imaging (2004) 31:1539-1540 and 1540-1543}

The online version of these original articles can be found at (for John Hardy)

http://dx.doi.org/10.1007/s00259-004-1676-9 and (for Agneta Nordberg)

http://dx.doi.org/10.1007/s00259-004-1677-8

In the Controversies section of Vol. 31 No. 11 the "For" and "Against" arguments were inadvertently exchanged and appeared under the wrong headings. The article by Agneta Nordberg should have appeared under "For", that by John Hardy under "Against".

Agneta Nordberg

Neurotec Department, Karolinska Institutet,

Karolinska University Hospital Huddinge B84,

141 86, Stockholm, Sweden

e-mail: agneta.nordberg@neurotec.ki.se

Tel.: +46-8-58585467, Fax: +46-8-6899210

J. Hardy $(\bowtie)$

Laboratory of Neurogenetics, National Institute on Aging,

National Institutes of Health, Building 35,

35 Convent Drive, Room 1A1015 MSC 3707,

Bethesda, MD 20892-3707, USA

e-mail: hardyj@mail.nih.gov 